\title{
Mechanical Behavior of Coke as a Material with Randomly Distributed Pores*
}

\author{
By Mitsutoshi ISOBE, ,* Kichiya SUZUKI,*** Mitsuru TATE*** and \\ Hideo KIT AGAWA $A^{* * *}$
}

\section{Synopsis}

A miniature bending test method was developed for measuring mechanical properties of coke with better accuracy. Mechanical properties of formed and conventional cokes at room temperature were measured by this method and the effects of pore on them were investigated, taking statistics into consideration. Deformation of a porous body was analyzed by the finite element method combined with Monte Carlo method and an attempt was made to develop a method to estimate Young's modulus of coke matrix.

The results are as follows.

(1) Linear correlation was found between Young's moduli of cokes and maximum bending stress, and a possibility of estimating the strength from the measurements of elastic deformation was shown.

(2) Young's modulus of coke decreased with increasing porosity. The decreasing rate of formed coke was different from that of conventional cokes.

(3) Young's modulus of coke matrix was estimated by the method presented here from apparent Young's moduli including the effects of pores.

(4) From a new viewpoint a comparison was made between the mechanical properties of formed coke and that of conventional one, using the Young's moduli of coke matrix obtained as above.

\section{Introduction}

The strength of metallurgical coke has been evaluated on the basis of tests at room temperature using a drum or a tumbler. Although recent attempts at the direct evaluation of hot strength have led to the development of some hot testing methods, unsolved problems still remain for the assurance of their universal availability; for instance, the correspondence between the new methods and the existing conventional methods is not affirmed clearly. ${ }^{1,2)}$

On the other hand, processes of making formed coke have been developed as a technique that may enable to utilize much amount of poorly- or noncoking coal for saving strong coking one whose supply will be increasingly short in the future. However, the quality of formed coke cannot be evaluated exactly by the conventional strength index, because a higher value in the drum index of the formed coke, which may result from its round shape and small porosity, does not always assure its satisfactory behavior in a blast furnace as good as or better than that of oven coke with proper drum index.

Generally speaking, the current testing methods are not sufficiently applicable for some kinds of coke, when they are quite different from the conventional one in the sorts of raw coals and/or the producing conditions. Thus, it is required to establish a new method, which enables to evaluate the hot strength of coke, far more exactly than the conventional methods, by a fundamental approach to the strength itself, not to its index. However, only following researches were carried out in this direction: measurement of Young's modulus with resonance-vibration method by Inoue and $\mathrm{Tani}^{3)}$; measurement of knoop hardness by Shiraishi et al. ${ }^{4)}$; indirect tensile test by Patrick and Stacey ${ }^{5}$; the same as above by Miyakawa and Fujishima, ${ }^{6)}$ which, alone, was applied to compare the mechanical properties of various formed cokes and oven cokes.

The aim of this study is to investigate the basic mechanical properties of coke at room temperature and to develop a testing method for them, from the standpoint of evaluating the statical strength or the load-carrying capacity of coke fundamentally. A miniature four-points bend test method was developed, which has the following merits: possibility of measuring with high accuracy the fundamental deformation and strength characteristics of small test pieces cut out of formed coke; application of static loadingand measuring-methods, but not of dynamic methods applied in the resonance-vibration method; possibility of measuring Young's modulus and maximum bending stress at once on a single test piece. Maximum stress and Young's modulus of various formed and oven cokes at room temperature were measured by the method and their correlation to the porosity was obtained. Statistical simulation analysis of elastic behavior of coke as a material with randomly distributed pores was performed, referring to a study on the analysis of grind stone with finite element method by Miyamoto et al. ${ }^{8-10}$ ) The elastic modulus of coke matrix was estimated from the results of the analysis and the apparent elastic modulus determined experimentally. The qualities of several sorts of formed as well as oven coke were compared by the moduli of coke matrix thus obtained.

\section{Experimental}

\section{Specimens}

Three kinds of formed coke, four kinds of oven coke and a kind of electrode graphite were used for tests. Their densities and porosities are shown in Table 1. The porosities of the formed cokes increase with the decrease of their true densities. The true densities of all the oven cokes are about $2 \mathrm{~g} / \mathrm{cm}^{3} \mathrm{ex}-$ cept for the coke A.

The sizes of formed coke A (pillow-type), B (Mashek-type) and $\mathrm{G}$ (pillow-type) are $62 \times 45 \times 35$

* Originally published in Tetsu-to-Hagané, 66 (1980), 803, in Japanese. English version received July 15, 1980.

** Formerly Graduate School, The University of Tokyo. Now at Kakogawa Works, Kobe Steel, Ltd., Kanazawa-cho, Kakogawa 675-01.

*** Institute of Industrial Science, The University of Tokyo, Minato-ku, Tokyo 106. 
$\mathrm{mm}, \quad 62 \times 45 \times 35 \mathrm{~mm}$ and $83 \times 56 \times 42 \mathrm{~mm}$, respectively.

Plate specimens of $41 \mathrm{~mm}$ long, 9 to $11 \mathrm{~mm}$ wide and 3 to $5 \mathrm{~mm}$ thick were cut from the pieces of the formed coke. Due to the existence of blow holes and cracks in the formed cokes the number of specimens obtained from each one piece is limited to four or so. The same specimens of oven coke were made from small lumps $(50 \times 50 \times 50 \mathrm{~mm}$ in size $)$ which were cut out of large lumps (about $400 \times 100 \times 100 \mathrm{~mm}$ in size). Because of high porosity of oven coke, only two or three specimens were obtained from one small lump.

The specimens were polished by emery paper, washed by water and dried in the electric drier at $150^{\circ} \mathrm{C}$ for $12 \mathrm{hr}$ or longer. The specimens went through the bend tests after the determination of apparent density by their weights and geometrical dimensions.

\section{2. $\quad$ Bend Tests}

The size of a test specimen and the principle of loading in the new miniature device for four-points bend test are shown in Fig. 1. To assure the accuracy of uniform pure bending, the frictional resistance of supporting-rolls was reduced as low as possible using miniature ball-bearings. An Instron-type uni-

Table 1. Physical properties of cokes.

\begin{tabular}{l|c|rrr}
\hline \multirow{2}{*}{ Kind of coke } & $\begin{array}{c}\text { True } \\
\text { density } \\
\end{array}$ & \multicolumn{3}{|c}{ Porosity (\%) } \\
\cline { 3 - 5 }$\left(\mathrm{g} / \mathrm{cm}^{3}\right)$ & mean & s.d. & data \\
\hline Formed coke A & 1.99 & 35.3 & 1.4 & 47 \\
Formed coke B & 1.85 & 36.5 & 3.3 & 86 \\
Formed coke G & 1.72 & 39.1 & 2.0 & 44 \\
Gonventional coke A & 1.91 & 45.5 & 1.5 & 31 \\
G.D.Q. & 2.00 & 48.4 & 1.8 & 44 \\
Conventional coke B & 1.97 & 50.7 & 3.2 & 23 \\
Gonventional coke G & 1.97 & 59.2 & 2.1 & 5 \\
Graphite & 2.10 & 17.6 & 1.1 & 8 \\
\hline
\end{tabular}

C.D.Q. : Dry-quenched coke

s.d. : $\quad$ Standard deviation

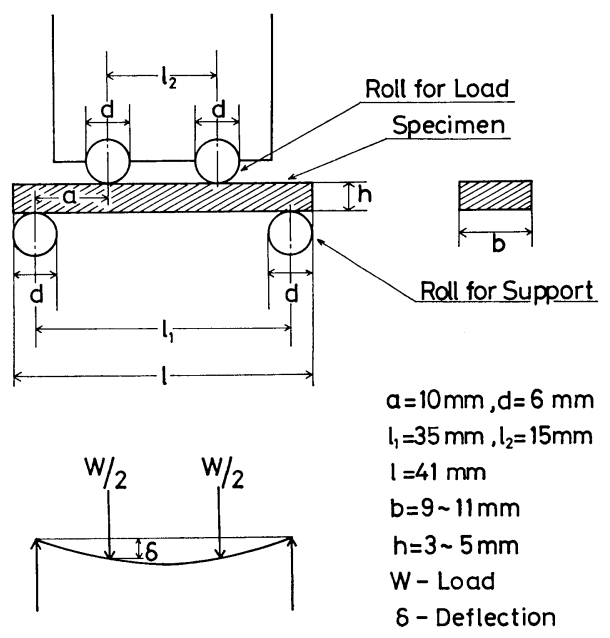

Fig. 1. Bending test. versal testing machine was used to give increasing load onto test specimens at a constant cross-head speed. A relation between the deflection at the center of a specimen, $\delta$, and total load, $W$, was determined. Young's modulus was calculated by the following equation:

$$
E=\frac{3}{b} \cdot \frac{a^{2}}{h^{3}}\left(l_{1}-\frac{4}{3} a\right) \cdot \frac{W}{\delta}
$$

The rigidity of the machine was determined by loading tests of graphite specimens with various thickness, $h$. The results are shown in Fig. 2. The deflections of the machine are given as the intersections of the straight lines with the ordinate. The relations of deflection $\delta v s .1 / h^{3}$ for different loads are found to be straight lines as seen in the lower part of Fig. 2. They give a linear relation against the loads as shown in the upper part of Fig. 2. No effect of specimen size on the Young's modulus, corrected for the deflection of the machine, could be observed within the ranges of $h=2 \sim 7 \mathrm{~mm}$ and $b=5 \sim 20 \mathrm{~mm}$. The cross head speed was fixed to be constant, $0.1 \mathrm{~mm} / \mathrm{min}$, because its change within the range of $0.1 \sim 10 \mathrm{~mm} / \mathrm{min}$ gave no effect on the results.

The maximum bending stress, $\sigma_{b \max }$, was calculated from the following equation, ${ }^{11)}$ using maximum load, $W_{\max }$, found in load $v s$. deflection curves shown in Fig. 3.

$$
\sigma_{b \max }=\frac{3 a}{b h^{2}} W_{\max }
$$
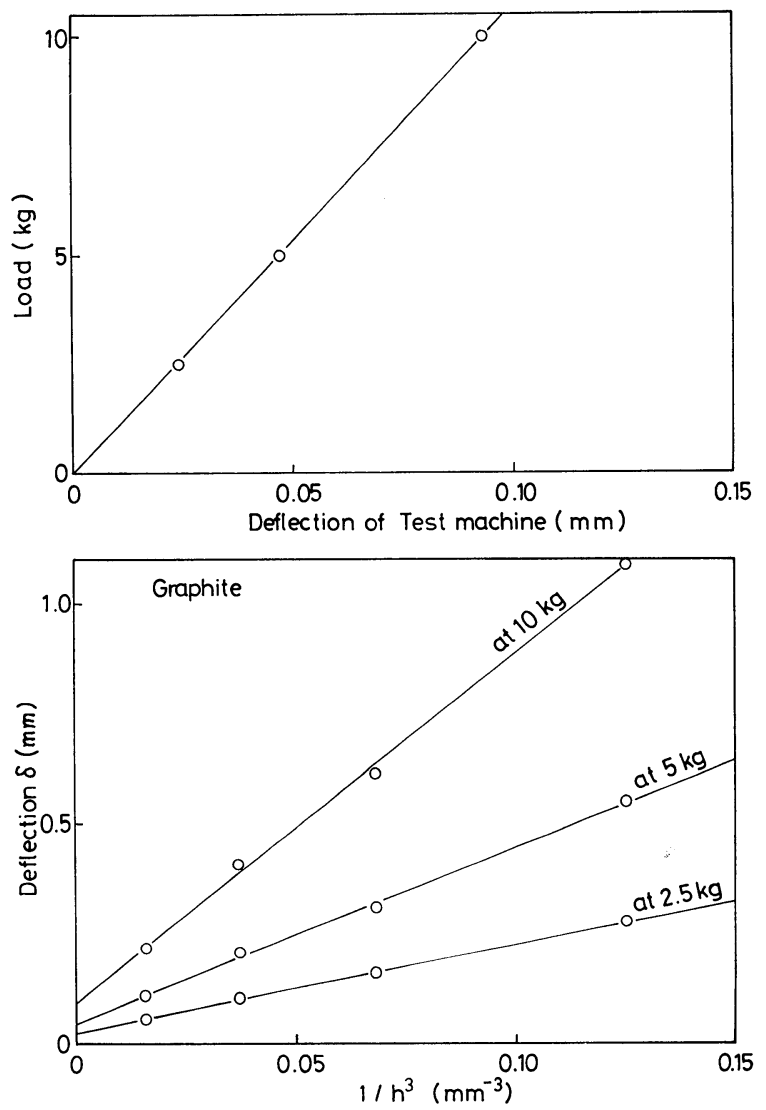

Fig. 2. Correction of Young's modulus. 
Poisson's ratio was measured during bending tests by a cross-strain gauge with a circular base adhered to the bottom surface of the specimens with $\alpha$-Gyanoacrylate adhesives.

\section{Porosity and Mode Pore Radius}

The true density of test specimens was measured based on the method specified by JIS-K2151, while the apparent density was estimated from the weight and volume of a specimen. The porosity was calculated from these two densities.

The mode pore radius was determined from the frequency distribution which was obtained by measuring the diameters of all pores found on the microphotographs of specimens used for bend tests. Some examples of microphotographs are shown in Photo. 1. Dark and dullish parts (a) or grayish parts (b) are pores. The portions in the grayish parts that look like aggregated fine pores or irregular network textures were regarded as inert textures and excluded from the measurements of pores. In case of formed coke $\mathrm{C}$, all of the textures were composed of very fine pores, whose sizes were too small to be measured. The shape of a pore section was considered to be an

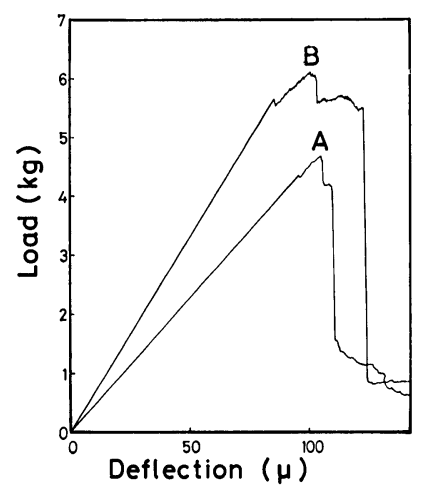

Fig. 3. Load $v s$. deflection curves. ellipse, whose area was calculated from the lengths of its major and minor axes. The radius of a circle having the same area as the ellipse was taken as the representative radius of the pore. The statistical distributions of pores were investigated for two formed cokes (A and B) and two oven cokes (A and C.D.Q.), observing five microphotographs arbitrarily selected from 56 ones for each specimen. Two specimens were taken for each coke. The total number of pores measured were about 1000 for formed coke and 500 for oven coke.

\section{Results}

\section{Load-Deflection Curves}

Typical examples of load-deflection curves obtained from bending tests are given in Fig. 3, where the ordinate is the sum of loads applied at the two inner loading points of a test specimen, $W$, and the abscissa is the deflection, $\delta$, or relative displacement of the loading points against the supporting points. The curves could be classified into two types, A and B. The type A showed a temporary stagnation or a drop of load (a step on the curve) at some level lower than the maximum load and a sudden falling down after passing through the maximum load. On the other hand, the type $\mathrm{B}$ showed the repetition of pulsative fluctuation of loads (a plateau on the curve) at the neighborhood of its maximum level and after that a sudden drop. Both types were observed in all sorts of cokes and the type A was observed most frequently in formed coke A which had the lowest porosity. The proportion of type $\mathrm{B}$ increased as the porosity increased. In case of formed coke $\mathrm{C}$, however, most of the curves were type $B$, indicating that a peculiar structure of the coke suggested by Photo. 1, might cause the instability of a whole specimen along with the succession of local small-scale fractures.

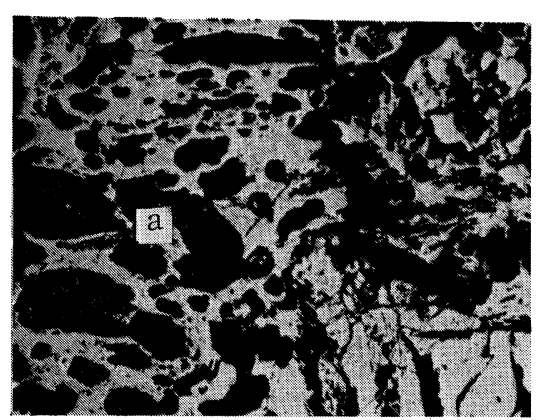

Formed Coke A

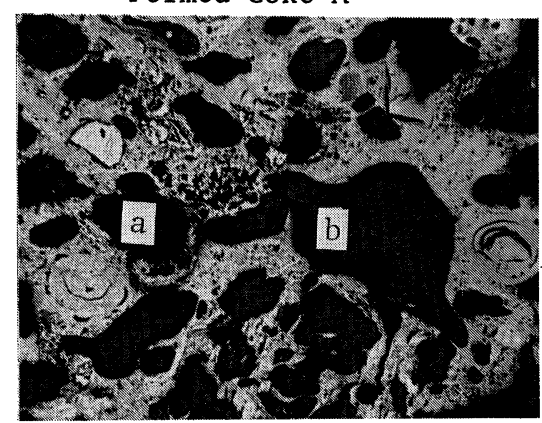

Conventiona1 Coke A

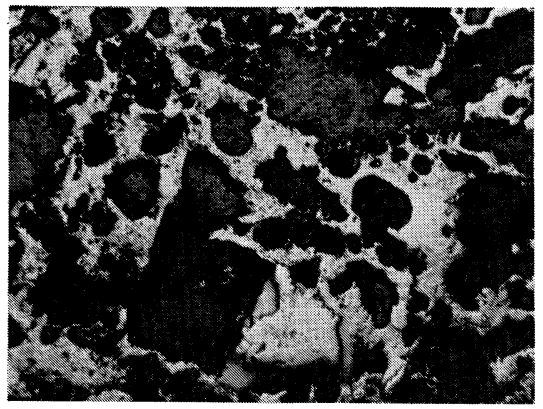

Formed Coke B

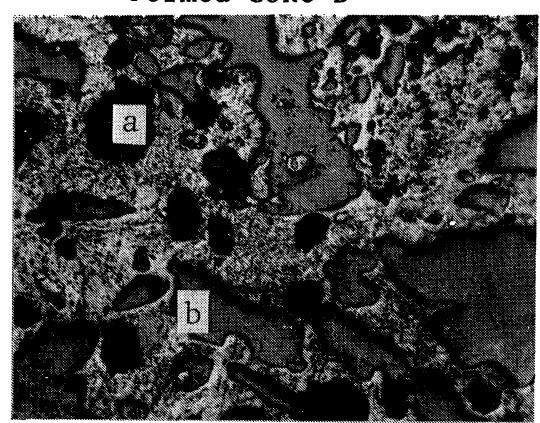

C.D.Q.

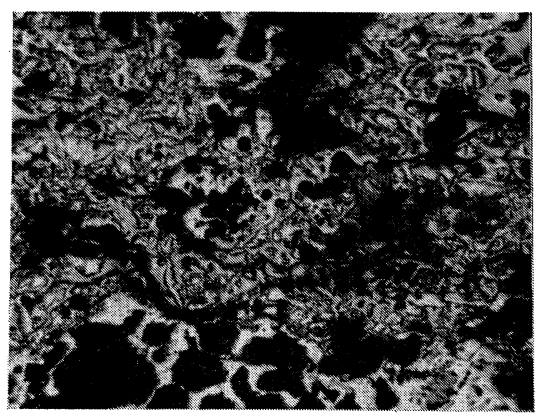

Formed Coke C

$200 \mu$

Photo. 1. Microstructures of formed and conventional cokes.

In the photographs, blurred dark (a) or gray parts (b) are pores. 


\section{Young's Modulus and Maximum Stress of Coke}

The relation between Young's modulus, E, and maximum stress, $\sigma_{b \max }$, shown in Fig. 4 indicates that there is a positive linear correlation between them irrespective of the sorts of coke. The regression line in the figure is expressed by the following equation:

$$
\sigma_{b \max }=0.23+0.00081 E\left[\mathrm{~kg} / \mathrm{mm}^{2}\right]
$$$$
\left(50 \mathrm{~kg} / \mathrm{mm}^{2}<E<1400 \mathrm{~kg} / \mathrm{mm}^{2}\right)
$$

where, the coefficient of regression: $r=89$

$$
\text { number of samples: } n=245 \text {. }
$$

Similar correlation was confirmed for cast iron, $\left.{ }^{12}\right)$ which is considered to show its behavior as a brittle material due to many internal defects. Coke seems to be similar to cast iron in this regard. The apparent Young's moduli of formed coke and oven coke are about $1000 \mathrm{~kg} / \mathrm{mm}^{2}$ and about $500 \mathrm{~kg} / \mathrm{mm}^{2}$ in average, while their values of maximum bending stress are about $1.0 \mathrm{~kg} / \mathrm{mm}^{2}$ and $0.6 \mathrm{~kg} / \mathrm{mm}^{2}$, respectively. It is possible to estimate the value of maximum bending stress approximately from Young's modulus on the basis of the positive correlation between them. The relation suggests also that the proof strength for fracture of coke is determined by deformation rather than by load.

The relation between maximum bending stress and porosity shown in Fig. 5 suggests a negative correlation as a whole. However, some different relations seem to exist in formed and oven cokes, and graphite shows considerably higher maximum bending stress than that of coke.

The relation between Young's modulus and porosity is shown in Fig. 6. The same tendency as in Fig. 5 is seen in Fig. 6, as the natural consequence of positive linear correlation between maximum bending stress and Young's modulus. In the load-deflection curves of graphite, a non-linear behavior was observed at the higher level of increasing load. Moreover, the relation between the experimental values of Young's modulus and maximum bending stress for graphite deviated far from the linear relationship for cokes shown in Fig. 4, as supposed from the comparison of Fig. 5 with Fig. 6 . These facts suggest that the unique behaviors of graphite shown in Figs. 5 and 6 are caused by its properties different from those of coke.

\section{Pore-radius Distribution of Coke}

The statistical distributions of pore-radius of formed and oven cokes obtained by observing microphotographs are shown in Figs. 7 and 8, respectively. The ordinate is the frequency (\%) of pore-radius weighted with sectional area, corresponding to the two-dimensional simulation analysis of the elastic behavior of coke described later. The distribution pattern at its peak is the sharpest in case of formed coke A and becomes flat gradually with increasing porosity, shifting its peak to the side of larger pore-radius. The mode pore-radius, or the pore-radius at the highest frequency $\bar{r}_{i}$, was obtained as follows as the root of mean square of the upper and lower limits of a radius

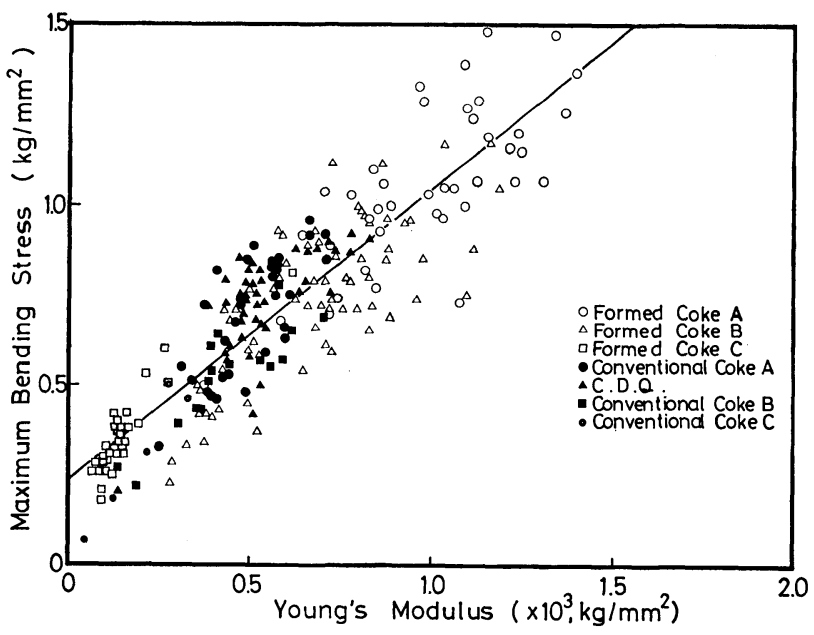

Fig. 4. Relation between Young's modulus and maximum bending stress.

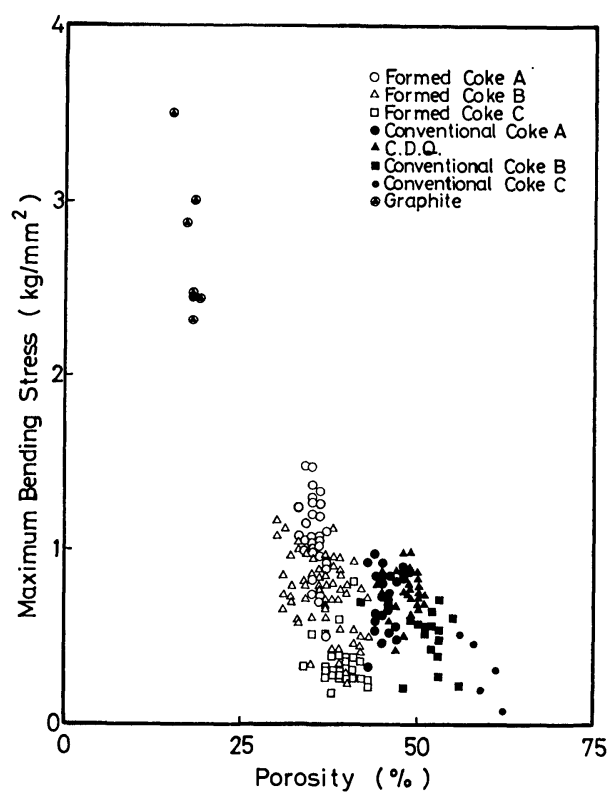

Fig. 5. Relation between maximum bending stress and porosity.

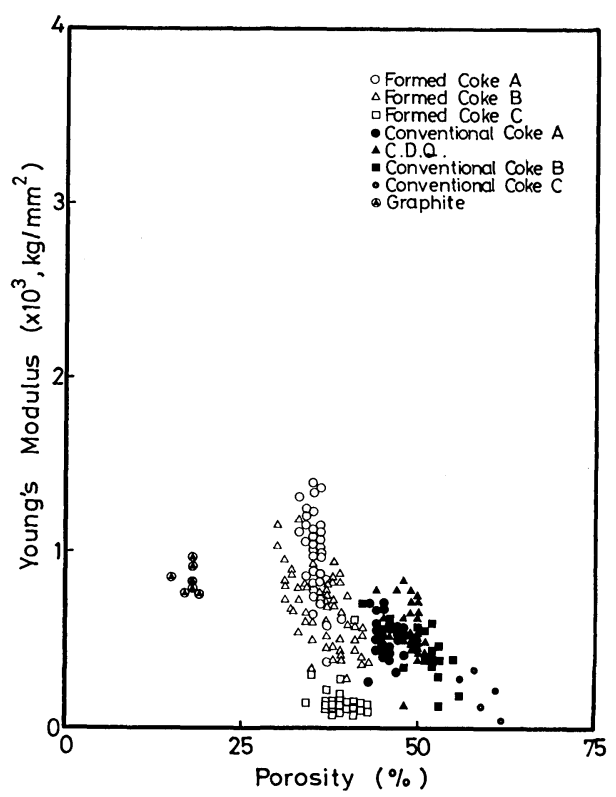

Fig. 6. Relation between Young's modulus and porosity. 

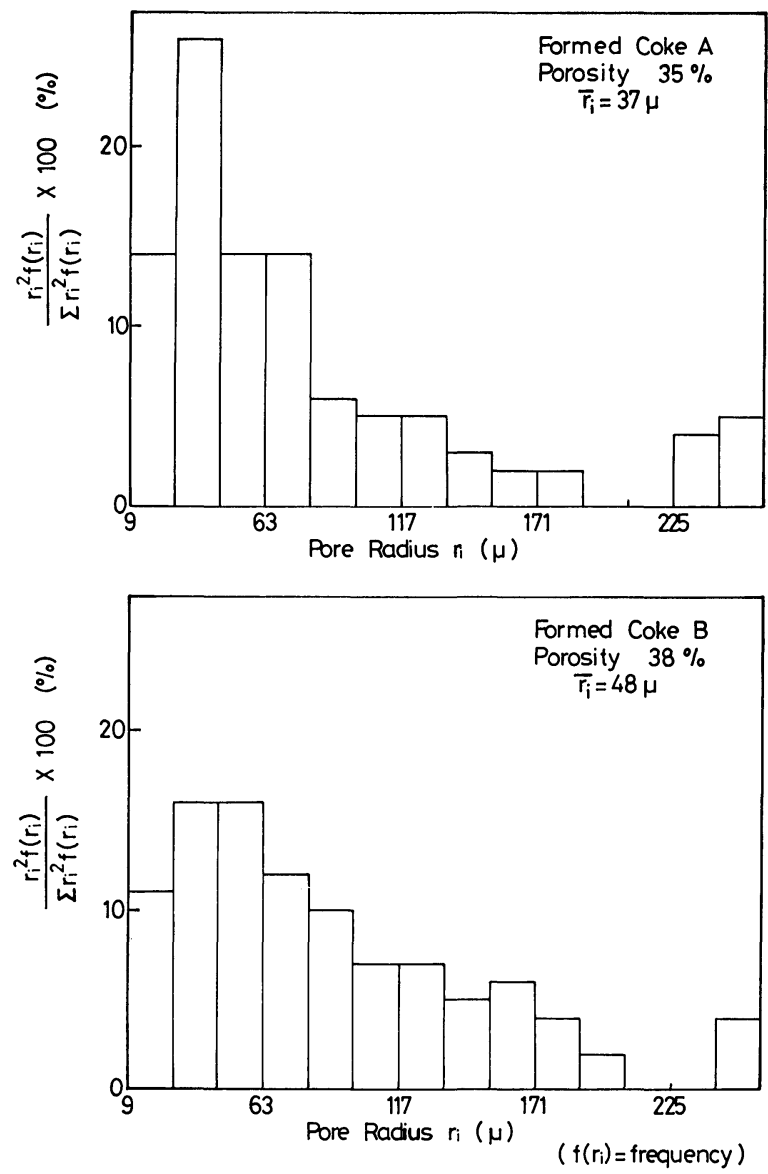

Fig. 7. Weighted frequency distributions of pore radius of formed coke.

range corresponding to the peak domain of histographs:

$$
\begin{aligned}
\text { Porosity } & (P)=35 \% \quad \bar{r}_{i}=\sqrt{\frac{27^{2}+45^{2}}{2}} \fallingdotseq 37(\mu) \quad \ldots \\
(P)=38 \% & \bar{r}_{i}=\sqrt{\frac{27^{2}+63^{2}}{2}} \fallingdotseq 48(\mu) \quad \ldots \\
(P) & =45 \% \quad \bar{r}_{i}=\sqrt{\frac{36^{2}+144^{2}}{2}} \fallingdotseq 105(\mu) \\
(P) & =48 \% \quad \bar{r}_{i}=\sqrt{\frac{63^{2}+171^{2}}{2}} \fallingdotseq 129(\mu)
\end{aligned}
$$

Equations (6) and (7) indicate that wide ranges had to be taken in case of oven cokes.

\section{Simulation of the Elastic Behavior of Coke}

\section{Modeling of Coke}

The values of Young's modulus of coke as a porous structure fluctuate considerably even at the same porosity as shown in Fig. 6. Assuming that the fluctuation results from the random distribution of radii, shapes, directions and positions of pores in the structure, an analysis based on a microscopic structural model and Monte Carlo method ${ }^{8-10}$ can be applied to coke. Coke is modeled as a two-dimensional structure consisting of two sorts of elements, matrix part (an element including no pore) and pore part (an element including a pore). Then two-dimensional elastic stress analysis by finite element method is repeatedly applied to every random arrangement of the
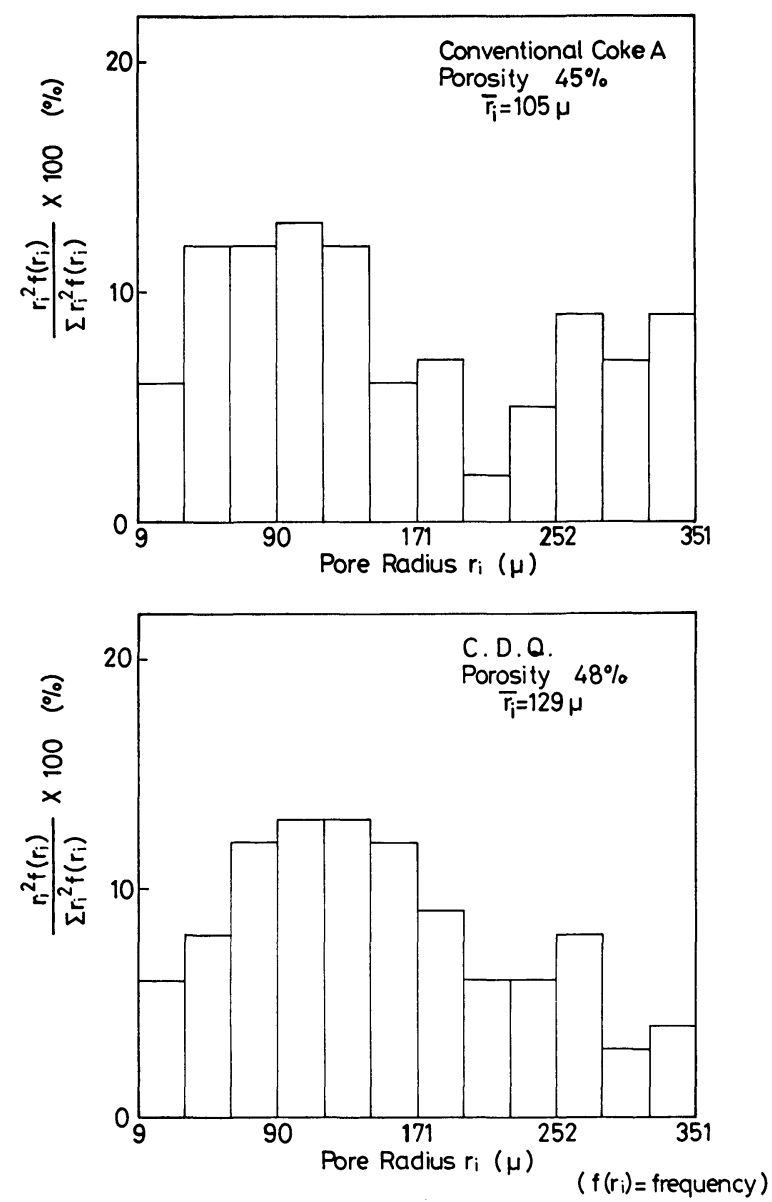

Fig. 8. Weighted frequency distributions of pore radius of conventional coke.

two parts.

The previous analyses of this kind seem to be developed to estimate the apparent elastic modulus of a porous material from the known elastic modulus of its matrix. In the present research, however, the analysis was applied to estimate Young's modulus and Poisson's ratio of the matrix from apparent ones obtained experimentally for the coke as a whole. Since coke in practical use is a porous material, the apparent Young's modulus is more important. However, it is still open to question whether the qualities of formed and oven coke (made by different processes) can be discussed only on the basis of their apparent physical properties. For example, plots on formed coke and oven coke in Fig. 6 appear to form their own groups according to the difference in the grades of porosity. This suggests that the apparent physical properties of formed coke are affected not only by its very small porosity caused directly by forming, but also by the change of properties depending on the sorts of raw coals. On the other hand, if Young's moduli of matrix parts (elements) can be estimated by the analysis, it will possibly serve as another criterion for comparing the mechanical properties of cokes excluding the effects of porosity.

\section{Simulation Procedure}

Simulation procedure is composed of the following steps as shown in Fig. 9. 
peatedly applied to every random arrangement of the two parts.

(1) Modeling of coke as a two-dimensional structure made up of two sorts of element, matrix part and pore part.

(2) Determination of the size of pore part.

(3) Determination of apparent elastic moduli and Poisson's ratios for pore part under an assumption on matrix part by stress analysis.

(4) Constitution of coke as a system with various random dispositions of two sorts of element and its stress analysis by finite element method using a pair of elastic moduli obtained in the step (3).

The steps (3) and (4) are repeated till the frequency distribution of apparent elastic moduli for the system obtained in the step (4) accords reasonably well with the frequency distribution determined by experiments.

\section{Size of Pore Part}

The size of an element having a single pore was determined by applying mode radius obtained by experiments to the pore and assuming its area to be $72 \%$ of total area. The number $72 \%$ was selected so as to fit for the division of a quarter of pore part into 60 finite elements in the stress analysis. If the number of finite elements greater than 60 were taken, an area ratio larger than $72 \%$ could be selected. Naturally the number $72 \%$ makes itself the upper limit of the system porosity, but it is sufficiently larger than the observed values of porosity.

\section{Stress Analysis of Pore Part}

An example of stress anlysis for a quarter of pore part is shown in Fig. 10.

The boundary condition was given as uni-axial compression with uniformly distributed displacement. The deformation is expressed a little exaggerately. Although the shape of pore was regarded as circular in the analysis, it would be able to assume elliptic pore in order to consider its anisotropic effects. Young's modulus was computed from the ratio of reactive force to displacements in the loading direction at the upper and lower edges. Poisson's ratio was computed from the ratio of mean horizontal displacement to that in the loading direction. Data used for the computation and results of analysis are given in Table 2. The adoption of the constant ratio of pore area $(72 \%)$ led to a constant Poisson's ratio similarly to that of matrix part. If Young's modulus of matrix part were assumed constant, that of pore part would also be constant. This shows that the ratio of matrix part number to pore part one plays an important role in the analysis of the system.

\section{Analysis of the System}

The procedure of analysis is as follows.

(1) Determination of the number of both elements according to the porosity at a given total number, which was taken to be $7 \times 7=49$ in this study.

(2) Finite element analysis of the system with a disposition of elements given by random number under the same boundary condition as that in the analysis of pore part and calculation of apparent Young's modulus and Poisson's ratio for the disposition. An example of the simulation of the system is shown in
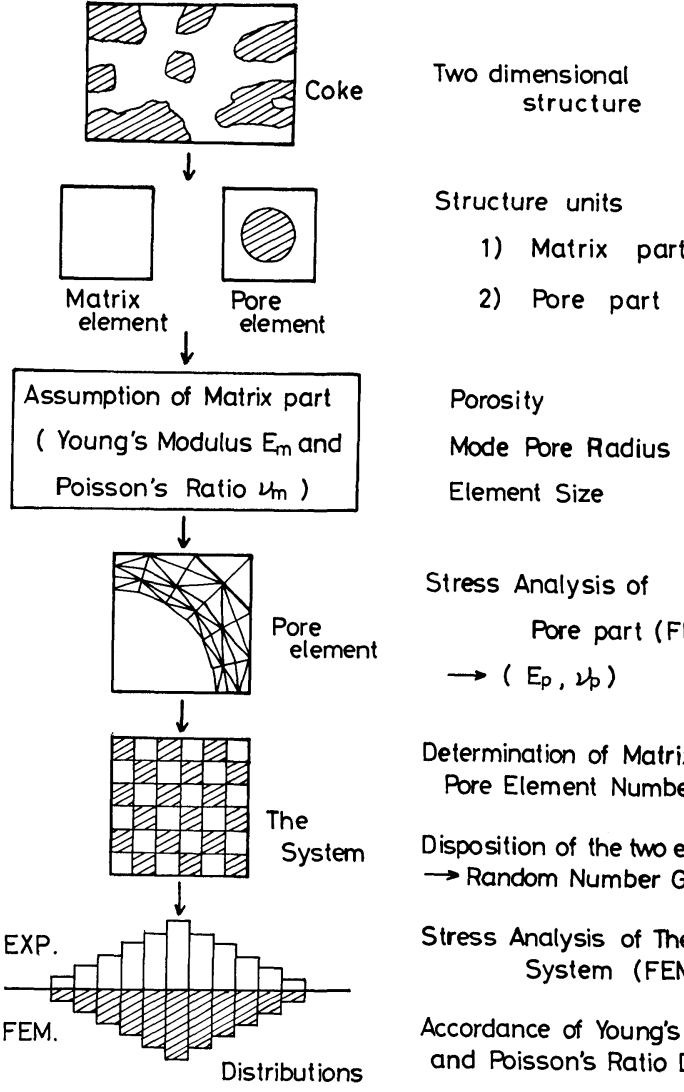

Stress Analysis of Pore part (FEM.)

$\rightarrow\left(E_{p}, \nu_{p}\right)$

Determination of Matrix and Pore Element Numbers

Disposition of the two elements $\rightarrow$ Random Number Generator

Stress Analysis of The System (FEM.)

Accordance of Young's Modulus and Poisson's Ratio Distributions

Fig. 9. Simulation method.

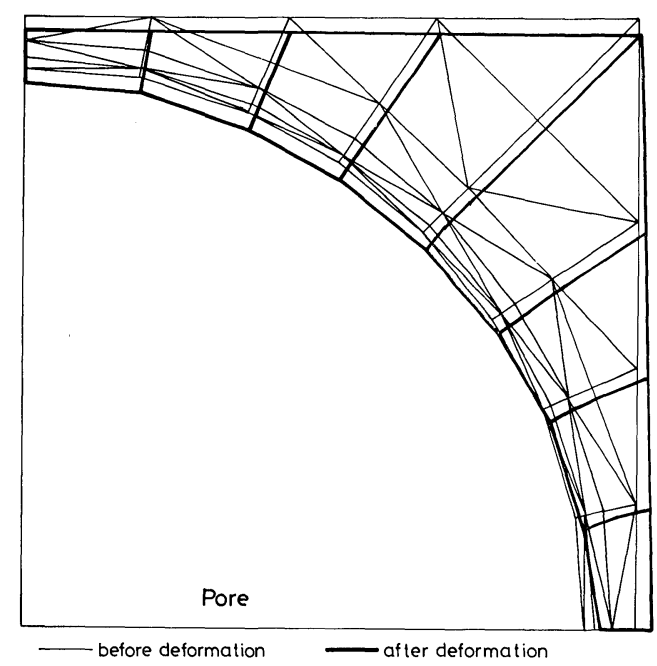

Fig. 10. Deformation of pore parts.

Fig. 11.

In the figure, pore parts are to locate at the positions where larger deformation is seen. It is considered that the identical values of Young's modulus and Poisson's ratio can be used for bending as well as for compression within the limit of elasticity.

The analysis and the calculation of apparent Young's modulus and Poisson's ratio was carried out at 25 different dispositions for a given porosity, (namely, for a sort of coke), to obtain the statistical distributions of the moduli. Comparing the distributions with those found by experiments, the simulation procedure was carried out repeatedly for various values 
of elastic moduli of matrix part as parameters. The true Young's modulus and Poisson's ratio of matrix part were determined as those that gave the reasonable coincidence of computed distributions with experimental ones.

\section{Results of Computation}

The simulation was applied to four kinds of coke, two formed and two oven cokes. The values of porosity, $P=35,38,45$ and $48 \%$ in the Table 2 correspond to formed coke A, formed coke B, oven coke A and G.D.Q., respectively. The ratio of matrix part number to pore part number was about 1: 1 at $P=35 \%$ and it decreased with the increase of porosity. Naturally, the system will be constituted of only pore parts at $P=72 \%$, and of only matrix parts at $P=0$.

In the actual computations, Young's modulus of matrix part was varied as a parameter, while Poisson's ratio of matrix part was kept constant for all sorts of coke. Because the observed values of apparent Poisson's ratio were less reliable, the value of Poisson's ratio of matrix part was selected so that the scattering range of calculated apparent values was smaller than that of the observed apparent values.

Table 2. Data of computer simulation.

\begin{tabular}{|c|c|c|c|c|c|c|}
\hline \multicolumn{3}{|c|}{ Number of elements } & \multicolumn{2}{|c|}{$\begin{array}{l}\text { Pore part } \\
\text { The system }\end{array}$} & \multicolumn{2}{|c|}{$\begin{array}{c}60 \\
7 \times 7=49\end{array}$} \\
\hline \multirow{2}{*}{ Matrix part } & $E$ & $\left./ \mathrm{mm}^{2}\right)$ & 3000 & 2100 & 2000 & 2300 \\
\hline & $\nu$ & & \multicolumn{4}{|c|}{0.01} \\
\hline \multicolumn{3}{|c|}{ Porosity, $P \quad(\%)$} & 35 & 38 & 45 & 48 \\
\hline \multicolumn{3}{|c|}{ Mode pore radius $\quad(\mu)$} & 37 & 48 & 105 & 129 \\
\hline \multicolumn{3}{|c|}{ Element size $\quad(\mu)$} & 77 & 100 & 220 & 270 \\
\hline \multicolumn{3}{|c|}{ Porosity of pore part (\%) } & \multicolumn{4}{|c|}{72} \\
\hline \multirow{2}{*}{ Pore part } & $E$ & $\left./ \mathrm{mm}^{2}\right)$ & 280 & 200 & 210 & 240 \\
\hline & $\nu$ & & \multicolumn{4}{|c|}{0.36} \\
\hline \multicolumn{3}{|c|}{ Number of matrix elements } & 25 & 23 & 18 & 16 \\
\hline \multicolumn{3}{|c|}{ Number of pore elements } & 24 & 26 & 31 & 33 \\
\hline
\end{tabular}

Loading Direction
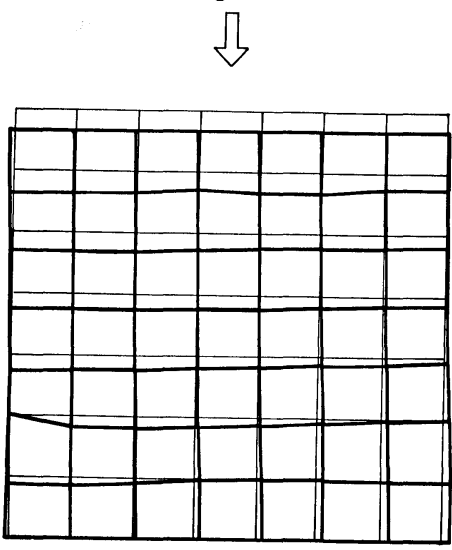

before deformation after deformation

Fig. 11. Deformation of the system.
Figure 12 and Table 3 show the results of computation for the Young's moduli and Poisson's ratio of matrix part given in Table 2 .

The mean values of calculated Young's moduli of the systems are a little smaller than the measured values as shown in Table 3 , but both values show a reasonably good accordance. While the calculated standard deviations remarkably decrease with the increase of porosity, the observed ones do not necessarily show the same tendency. The mean values of calculated Poisson's ratio are not necessarily in accordance with those of observed Poisson's ratio, but

Table 3. Young's modulus $E$ and Poisson's ratio $\nu$ of coke.

\begin{tabular}{|c|c|c|c|c|c|c|}
\hline \multicolumn{3}{|c|}{ Porosity (\%) } & 35 & 38 & 45 & 48 \\
\hline \multirow{8}{*}{$\begin{array}{c}E \\
\left(\mathrm{~kg} / \mathrm{mm}^{2}\right)\end{array}$} & \multirow{3}{*}{ EXP. } & mean & 1070 & 660 & 530 & 540 \\
\hline & & s.d. & 160 & 160 & 100 & 120 \\
\hline & & n.s. & 25 & 25 & 25 & 25 \\
\hline & \multirow{3}{*}{ GAL. } & mean & 1040 & 640 & 500 & 520 \\
\hline & & s.d. & 110 & 70 & 50 & 30 \\
\hline & & n.d. & 25 & 25 & 25 & 25 \\
\hline & \multirow{2}{*}{\multicolumn{2}{|c|}{$\begin{array}{l}\text { Series model } \\
\text { Parallel model }\end{array}$}} & 560 & 360 & 320 & 350 \\
\hline & & & 1610 & 1010 & 830 & 870 \\
\hline & \multirow{3}{*}{ EXP. } & mean & 0.20 & 0.21 & 0.22 & 0.21 \\
\hline & & s.d. & 0.03 & 0.07 & 0.07 & 0.05 \\
\hline & & n.s. & 7 & 14 & 17 & 13 \\
\hline & \multirow{3}{*}{ CAL. } & mean & 0.16 & 0.18 & 0.22 & 0.24 \\
\hline & & s.d. & 0.02 & 0.02 & 0.02 & 0.02 \\
\hline & & n.d. & 25 & 25 & 25 & 25 \\
\hline
\end{tabular}

s.d. : Standard deviation

n.s. : Number of specimens

n.d. : Number of different dispositions

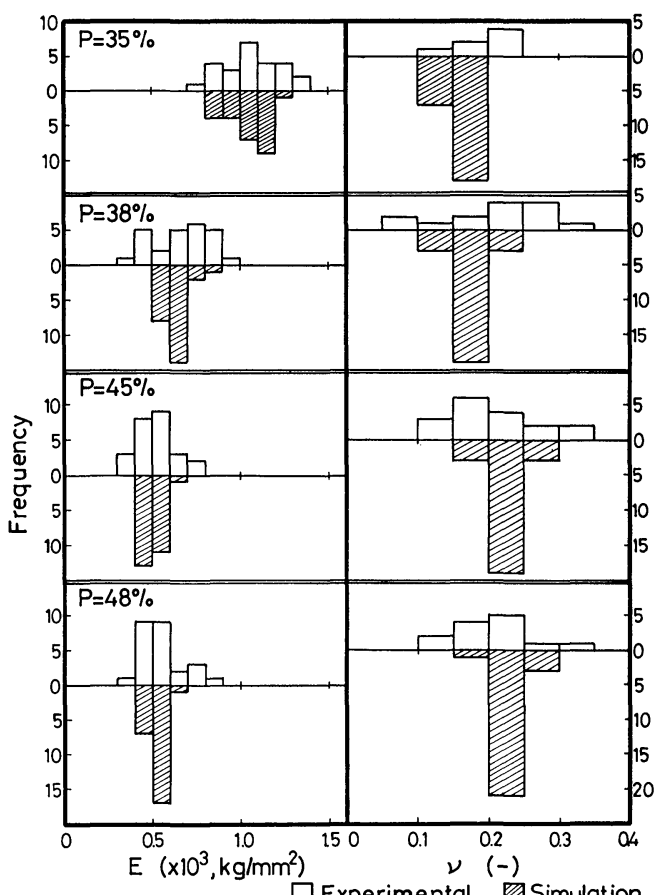

Fig. 12. Simulation result of Young's modulus $(E)$ and Poisson's ratio (v). 
the calculated deviations are sufficiently smaller than the observed ones. After all, the results show that Young's modulus of matrix part differs with sorts of coke.

\section{Consideration}

\section{Law of Mixture}

According to the law of mixture, the upper and lower limits of elastic moduli of particle dispersed composite materials are generally given by the parallel and the series models ${ }^{13)}$ shown in Fig. 13, respectively. They were applied to coke as a system consisting of matrix and pore parts to examine the variation of apparent Young's modulus with porosity at constant matrix Young's modulus irrespective of coke sorts. The results of calculation at matrix Young's modulus equal to $1070 \mathrm{~kg} / \mathrm{mm}^{2}$ (corresponding to the porosity of 35\%) are shown in Fig. 14. The two solid lines and white dots in the figure show calculations by the equations described in Fig. 13 and by finite element method, respectively. The latters are all found within the area restricted by the formers. This means that the finite element method gives a nallow range between the upper and lower limits in comparison with the law of mixture, because of the coexistence of different parts in a row or column of the dispositions corresponding to the maximum $\left(\bar{E}_{\max }\right)$ and the minimum $\left(\bar{E}_{\min }\right)$ as shown in Fig. 13. The experimental values expressed by their mean and fluctuation range are completely included in the area between the upper and lower limits in case of coke with porosity equal to $35 \%$, but not in case of cokes with porosity larger than $35 \%$ probably due to the assumption of constant matrix Young's modulus. These results show the appropriateness of the computation by the statistical simulation and finite element method. They also show that the Young's modulus of matrix part should be evaluated as the property different with the sorts of coke.

\section{Young's Modulus and True Density of Matrix Part}

Figure 15 shows a relation between the Young's modulus and the true density of matrix parts. It suggests positive correlation between them and some difference between formed coke and oven coke in the correlation.

\section{Conclusion}

A new method of testing coke strength by miniature four-points bending apparatus was applied to the measurement of the fundamental mechanical properties of various formed and oven cokes and their dependence on the porosity was studied. By the simulation analysis of elastic behavior of coke as a porous material Young's moduli of matrix parts were estimated. The following informations were obtained.

(1) The miniature bending test was able to show

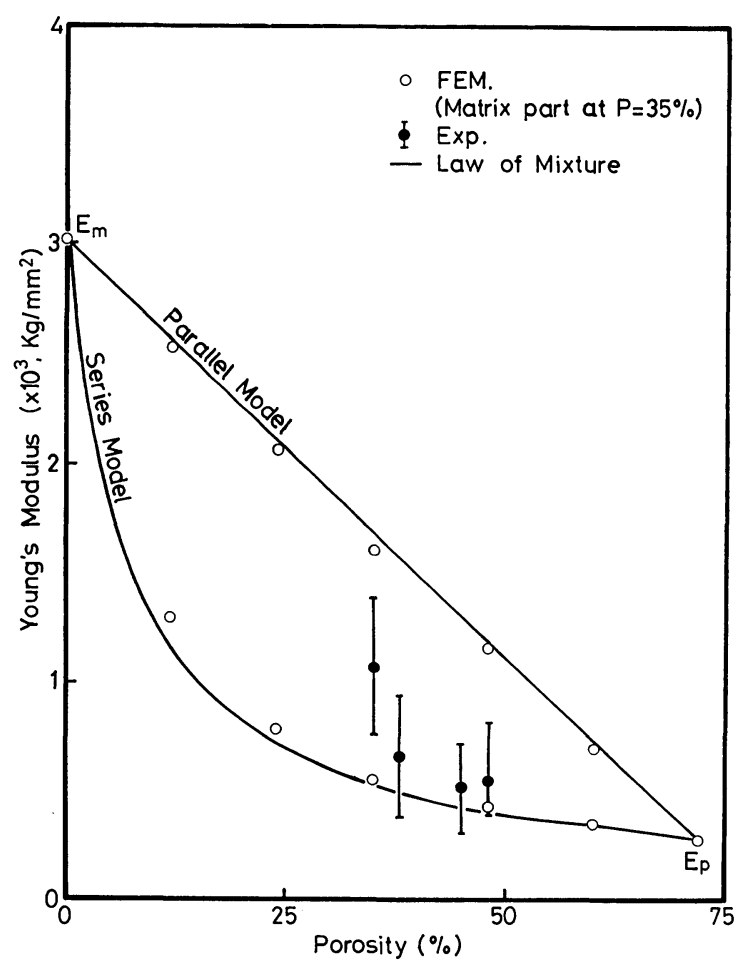

Fig. 14. Law of mixture.

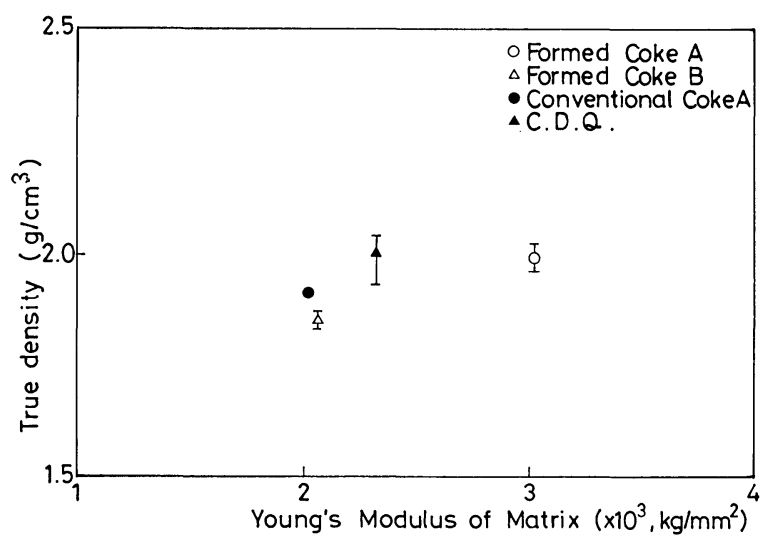

Fig. 15. Relation between Young's modulus of matrix and true density.

Fig. 13. Series model and parallel model.

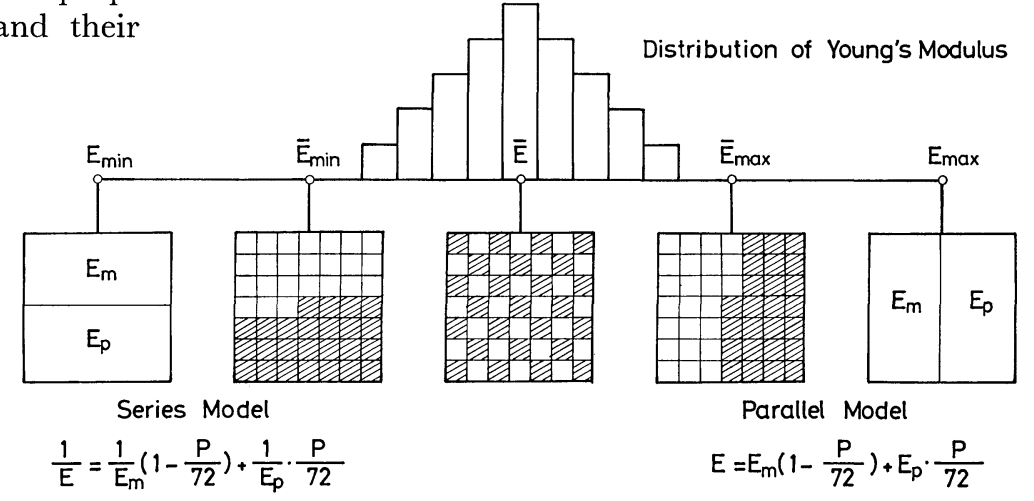


directly the difference between formed coke and oven coke at room temperature in their mechanical strength.

(2) General positive correlation was found between apparent Young's modulus and maximum bending stress regardless of coke sorts. The relation may be utilized for the estimation of coke strength from its Young's modulus.

(3) Coke can be modeled as a material whose pores distribute randomly in size and disposition. Simulation analysis of the model enables to understand the reason why coke strength fluctuates and to estimate the Young's modulus of coke matrix.

(4) Matrix Young's moduli may serve as new criterion for comparing the mechanical properties of various cokes.

Although the present study is restricted to the mechanical properties of coke at room temperature, it brings forward some subjects to be investigated hereafter for the purpose of evaluating hot strength of coke appropriately, as follows: measurements of mechanical properties of matrix part at elevated temperature by bending test; change of pore conditions due to reaction with $\mathrm{CO}_{2}$ and its effects on the mechanical properties.

\section{Acknowledgements}

The authors would like to thank Prof. Inoue, Chiba University, Assist. Prof. Honma, The University of
Electro-communications, Mr. Ogura, Institute of Industrial Science, The University of Tokyo, and Mr. Terasawa, Waseda University, for their advice and assistance.

\section{REFERENCES}

1) Y. Jōmoto, H. Matsuoka, S. Honba and K. Yonezawa: Coke Circular, 18 (1969), 126.

2) S. Ida, T. Nishi and K. Nakama: Coke Circular, 21 (1972), 252.

3) K. Inoue and H. Tani: J. Fuel Soc. Japan, 33 (1954), 587.

4) M. Shiraishi, J. Kumai, H. Kimura and Y. Yoshida: $J$. Fuel Soc. Japan, 46 (1967), 483.

5) J. M. Patrick and A. E. Stacey: Fuel, 51 (1972), 81, 174, \& 206, 52 (1973), 27, and 54 (1975), 213 \& 256.

6) A. Miyakawa and I. Fujishima: J. Fuel Soc. Japan, 54 (1975), 983 and 55 (1976), 30.

7) F. Nagai, K. Sato and T. Kanda: J. Mat. Sci. Soc. Japan, 12 (1975), 56.

8) H. Miyamoto, Y. Ishijima and K. Honma: Proc. First Int'l Conf. of Mechanical Behavior of Materials, Vol. IV, The Soc. of Mat. Sci., Japan, Kyoto, (1972), 484.

9) H. Miyamoto, J. Oda and S. Sakata: J. Japan Soc. Mech. Eng., 77 (1974), 146.

10) H. Miyamoto, J. Oda and S. Sakata: Trans. Japan Soc. Mech. Eng., 41 (1975), 748.

11) Handbook of Mechanical Engineering, The 5th Ed., ed. by The Japan Soc. Mech. Eng., Vol. 4, (1968), 42.

12) S. Oki and N. Kayama: Melting and Casting, Foundry, Asakura Shoten, Tokyo, (1962), 176.

13) T. Fujii: J. Soc. Mat. Sci., Japan, 25 (1976), 199. 